\title{
Liquid Loading in Gas Wells: from Core-Scale Transient Measurements to Coupled Field-Scale Simulations
}

\author{
Xiaolei Liu, ${ }^{\text {a, }}, 1$ Gioia Falcone, ${ }^{\text {b }}$ and Catalin Teodoriu ${ }^{\mathrm{c}}$ \\ a Institute of Petroleum Engineering, University, Clausthal University of Technology, 38678, Clausthal-Zellerfeld, \\ Germany \\ ${ }^{\mathrm{b}}$ Oil and Gas Engineering Centre, Cranfield University, MK43 OAL, Cranfield, UK \\ ${ }^{\mathrm{c}}$ Mewbourne School of Petroleum and Geological Engineering, The University of Oklahoma, 73019-1003, \\ Oklahoma, USA
}

\begin{abstract}
Liquid loading is a major operational constraint in mature gas fields around the world. It manifests itself as an increasing back pressure on the reservoir due to a rising liquid column in the well, which initially decreases deliverability, then ultimately causes the gas well to cease production. Theoretically, every gas well will experience this debilitating phenomenon in the latter stages of its producing life.
\end{abstract}

In this paper, both laboratory experiments and numerical simulations are presented to shed more light on the physical process of liquid loading, with a focus on reservoir responses. On the one hand, core-flooding experimental setups of different scales were designed and constructed to investigate back pressure effects on transient flow through the near-wellbore region of the reservoir. On the other hand, the modelling of a gas well undergoing controlled flow and shut-in cycles was performed to validate core-scale observations at reservoir scale, using commercial integrated numerical software that connects a transient wellbore model to a transient reservoir model. The simulated transient characteristics of short-term downhole dynamics (e.g. liquid re-injection and co-current/counter-current flows) supported the Ushaped concept observed in the experiments.

The detected temporal distribution of pore fluid pressure within the reservoir medium itself (referred to as the U-shaped pressure profile) was observed both experimentally at the corescale and numerically at the reservoir-scale. This pressure distribution can be used to explain re-injection of the denser phases into the near-wellbore region of the reservoir.

Keywords: Liquid loading; Gas wells; Core-flooding experiments; Integrated wellborereservoir simulations

\section{Introduction}

\subsection{Liquid loading}

As an energy form significantly cleaner than coal and oil, natural gas creates a strong market demand and offers economic benefits. Hence, there is an increasing need to improve the recovery efficiency from existing gas fields. Liquid loading is a common problem that restricts natural gas production in mature fields as the produced gas cannot lift associated liquids from the wellbore to surface. This results in liquids accumulating at the bottomhole, such that the growing column of liquid causes a back pressure in the near wellbore region of the reservoir, which impairs the continuity of gas production. As illustrated in Fig. 1, the typical process of liquid loading can be divided into five stages (Lea et al., 2003):

1) When natural gas begins to flow into the wellbore at the start of production, the gas can

\footnotetext{
Corresponding author (now with Cranfield University), E-mail: Xiaolei.Liu@cranfield.ac.uk (X. Liu).

${ }^{1}$ Present Address: Oil and Gas Engineering Centre, Cranfield University, MK43 0AL, Cranfield, UK.
} 
transport all co-produced liquids to the surface with a relatively high gas velocity. At this early stage, there will be no liquid accumulation at the bottomhole (Fig. 1 a); the gas flow rate in the wellbore is greater than the critical flow rate required to remove liquids in the gas stream; the liquid phase is carried by the gas phase along the tubing in the form of minor droplets and films within a mist/annular flow regime.

2) As a result of reservoir pressure depletion, gas velocity becomes insufficient to lift coproduced liquids, followed by a rise in liquid content in the wellbore. This event causes some of the liquid droplets or liquid films to flow backwards to the bottomhole, which creates a liquid column (Fig. 1 b). At this stage, the gas flow rate in the wellbore is lower than the critical flow rate; the flow pattern can transmute from a mist/annular flow regime to that of a churn/slug flow regime.

3) The low gas flow rate continues to increase the liquid content, which in turn raises the height of the liquid column at the bottomhole, creating a higher hydraulic pressure downhole (Fig. $1 \mathrm{c}$ ). During this period, the gas well will experience a bubble flow regime.

4) When the hydraulic head downhole is high enough, the gas stream in the wellbore will be paused as a result of high back pressure. In addition, the accumulated liquids will begin to be re-injected into the near wellbore region of reservoir. (Fig. $1 \mathrm{~d}$ )

5) When the near-wellbore reservoir recovers sufficient energy or the cumulated liquids are artificially removed during the shutdown period, the upwards gas flow may be attained once again, carrying liquids in the wellbore to the surface (Fig. 1 e).

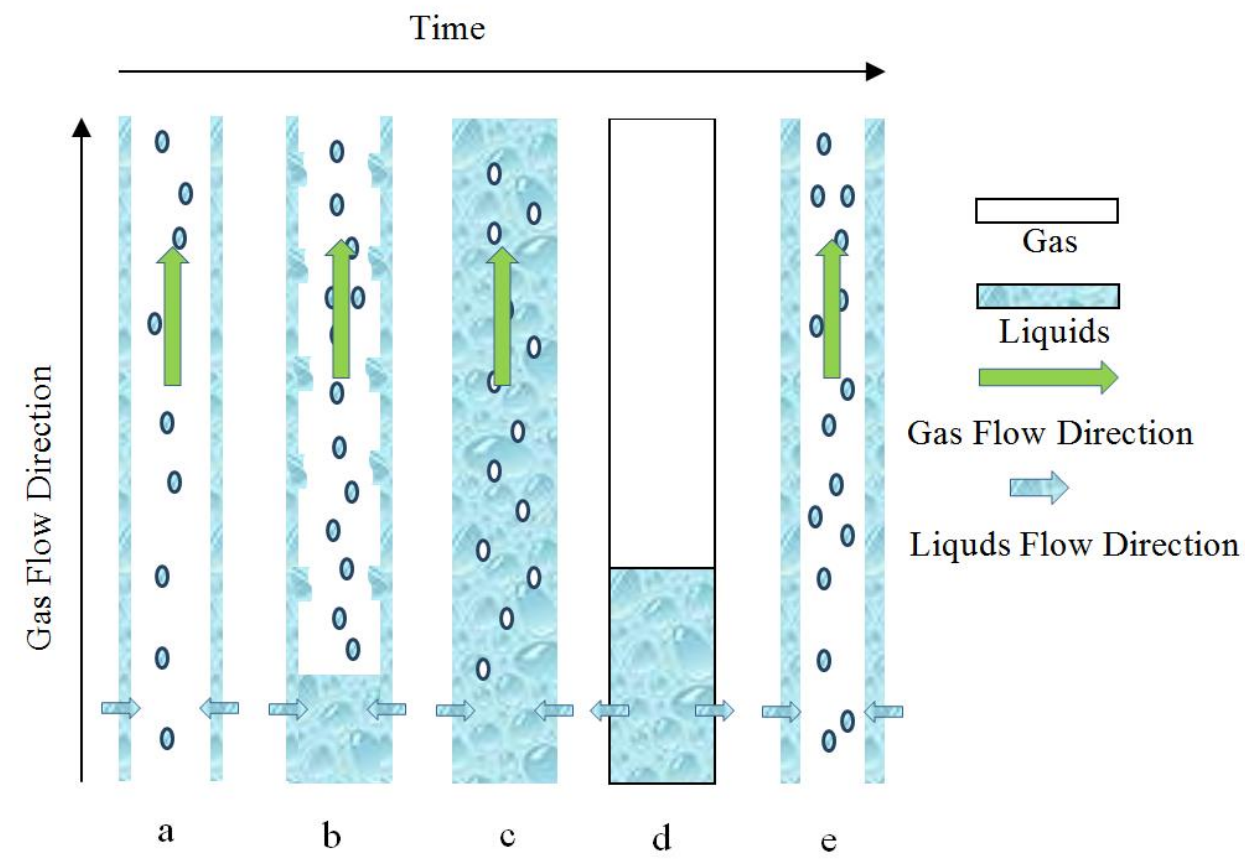

Fig. 1 - Schematic description of typical liquid loading process.

\subsection{Current prediction approaches}

The most widely used and generally accepted approach for predicting the onset of liquid loading is to evaluate the so-called "critical flow rate" through some well-established correlations. The empirical expression most favoured by the petroleum industry is the Turner correlation (Turner et al., 1969), which states that liquid droplet flow reversal triggers the onset of liquid loading. This critical velocity model is based on the force balance between the largest liquid droplet and the upward gas flow in the wellbore (see Fig. 2). 

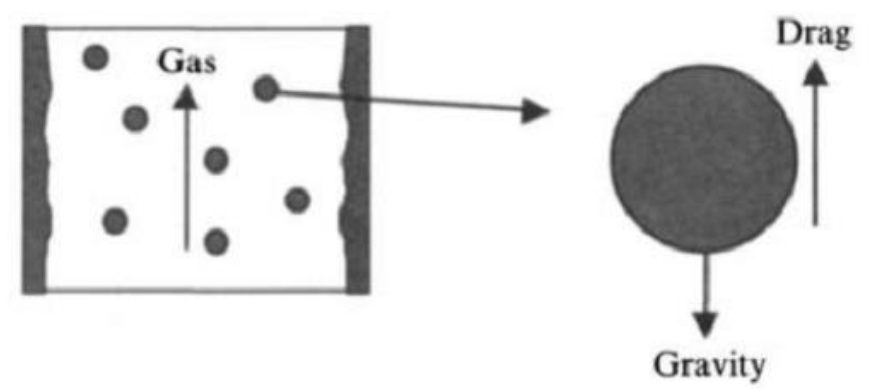

Fig. 2 - Liquid droplets transport in a vertical gas stream (Lea et al., 2003).

Based on observed field data, Turner et al. (1969) proposed a liquid droplet model that could provide reasonable prediction results with an adjustment factor of $20 \%$. The integrated Turner critical gas velocity equation is:

$$
v_{g}=\frac{1.3 \sigma^{1 / 4}\left(\rho_{L}-\rho_{g}\right)^{1 / 4}}{C_{d}^{1 / 4} \rho_{g}^{1 / 2}}
$$

where $v_{g}$ is the gas velocity in $\mathrm{ft} / \mathrm{sec}, \sigma$ is the interfacial tension in dynes $/ \mathrm{cm}, \rho_{L}$ is the liquid density in $\mathrm{lbm} / \mathrm{ft}^{3}, \rho_{g}$ is the gas density in $\mathrm{lbm} / \mathrm{ft}^{3}$, and $C_{d}$ is the drag coefficient.

The industry has gained considerable experience in applying the Turner equation in different scenarios and how to modify it to match field observations. As presented in Table 1, several investigators have suggested different modified expressions derived from Turner model.

Table 1 - Review of Turner Equations.

\begin{tabular}{|c|l|}
\hline Authors & Modifications of Turner correlation \\
\hline Turner et al., 1969 & Created the widely accepted Turner equation \\
\hline Coleman et al., 1991 & $\begin{array}{l}\text { Suggested not to use the 20\% correction factor for low pressure } \\
\text { gas wells }\end{array}$ \\
\hline Nosseir et al., 2000 & Considered influences from different flow regimes \\
\hline Li et al., 2002 & Involved the droplets' shape \\
\hline Veeken et al., 2003 & Defined the concept of Turner ratio \\
\hline Guo et al., 2006 & Took the minimum required kinetic energy of gas flow into account \\
\hline Belfroid et al., 2008 & Concerned with the effects due to wellbore inclination \\
\hline Sutton et al., 2010 & Used more realistic PVT properties \\
\hline Zhou and Yuan, 2010 & Included the liquid droplet concentration in gas wells \\
\hline Veeken et al., 2010 & Designed a specific expression for offshore gas wells \\
\hline Luan and He, 2012 & Comprised droplets rollover in the gas rising process \\
\hline
\end{tabular}

The likely reason that Turner's method is so popular is that all the parameters needed in the predictive equation can be readily obtained at the wellhead, which is a great convenience for field operators. In this way, operators could save the trouble of acquiring bottomhole data and so keep down operating costs. In practice, when the 'theoretical' Turner correlation is applied to a specific gas well, a coefficient is generally required to 'adjust' the equation to better fit the situation in the field. This indicates there is inherent uncertainty in a global application of the Turner method.

Turner et al. presented that liquid droplet reversal is primarily responsible for the onset of 
liquid loading, because it better matches the field data used. This assumption also became the most significant theoretical basis of the conventional Turner correlation. However, some extensive reviews have suggested that the occurring occurrence of liquid loading is associated with liquid film flow reversal instead (Van't Westende, 2008; Veeken and Belfroid, 2010; Waltrich, 2012), and this finding has thrown doubt upon the theoretical foundation of the Turner model.

As stated by Veeken and Belfroid (2010), the practical success of Turner equation is not a coincidence, because the physical theory behind liquid droplet flow reversal and liquid film flow reversal (an equilibrium between drag force and gravity) are actually similar. It could be expected that Turner correlation will still be the most notable prediction method for liquid loading in the near future.

In recent decades, considerable research has been conducted on liquid loading and many well established approaches have been used to alleviate its effects on gas production. However, the current methods for modelling/predicting liquid loading have oversimplified the role of near wellbore reservoir. In most instances, even though a multiphase transient wellbore model is employed, the corresponding reservoir model is still based on steady state or pseudo steady state approaches. In some cases, the reservoir is just simply described by the inflow performance relationship. Yet, as liquid loading is a time-dependent phenomenon, the application of steady/pseudo steady state reservoir model may be inappropriate. In a petroleum production system, the reservoir inflow is always the starting point, but it is often the most underappreciated and oversimplified element in the process.

Due to the limitation of steady/pseudo steady state models and the complexity of liquid loading process, an efficient tool that can integrate the flows in the reservoir and in the wellbore has been longed for by the industry. An integrated model, which can couple transient models of both reservoir and wellbore model, is believed to be the most reliable way of predicting the onset of liquid loading, describing the subsequent transient phenomena and selecting the optimum liquid unloading technique. Some studies have been implemented in this area and achieved satisfactory results. Denney (2007) presented predictions of transient flow in liquid loaded gas wells through an implicit coupling between wellbore and reservoir models. Schiferli et al. (2010) investigated the performance of transient wellbore/reservoir modelling through coupling a commercial code and an in-house near wellbore reservoir simulator, which successfully presented the liquid accumulation process in the near wellbore region during liquid loading. Hu et al. (2010) used the wellbore-reservoir transient modelling method (Sagen et al., 2011) to evaluate the cycling capability of gas wells under liquid loading conditions. In the view of laboratory tests, Fernandez et al. (2010) designed a high-pressure flow loop to integrate a vertical tube representing the wellbore with a porous medium that can mimic the near-wellbore region of the reservoir.

\section{Research methodology}

This paper is aimed at devising a series of experimental and numerical studies to understand near-wellbore dynamics in gas wells. Firstly, a small-scale core-flooding experimental setup was introduced to study back pressure effects on transient flow through porous media, using a modified Hassler cell, mimicking the effect of varying downhole pressure. After that, based on the results from the small-scale tests, a large-scale core-flooding experimental apparatus was designed and custom-made, where a larger-than-standard hydrostatic core holder was included.

Due to the limited size of the core plugs used in both sets of laboratory experiments, one fundamental question left was whether these core samples actually possessed the aptitude to characterise a real near-wellbore reservoir. As field-scale experiments on the physics investigated here were not feasible, a reservoir-scale model with a drainage area of $1800 \mathrm{~m}$ 
was built to consolidate the understanding of the transient phenomena from the core-scale experiments. A comparison of the drainage radius in the tested gas well and the length of rock samples used in the core-flooding experiments at different scales is shown in Fig. 3. The chosen drainage area is much larger than formation samples, thus having the potential to provide a wealth of information on downhole dynamics at field scale.
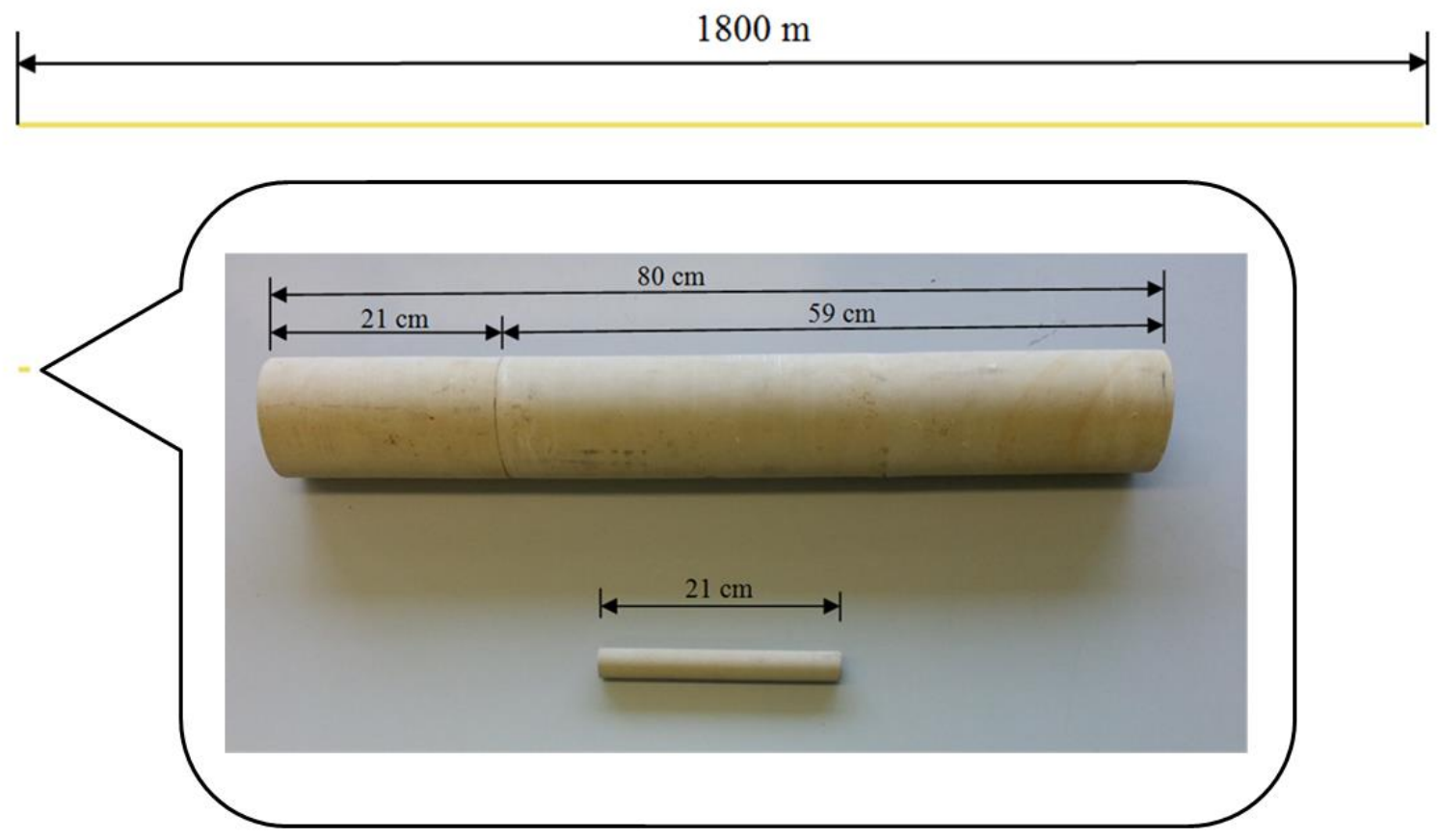

Fig. 3 - Comparison of the drainage radius in the integrated wellbore/reservoir simulations at field-scale and the size of the core samples used in the small- and large core-scale core flooding experiments.

\section{Pressure distributions and flow directions in the near wellbore reservoir under liquid loading conditions}

Due to the wellbore phase redistribution that occurs during liquid loading, the bottomhole pressure changes over time. The frequency and amplitude of these pressure changes vary with the magnitude of liquid loading occurrence. The conventional pressure profile in the near-wellbore region (Fig. $\mathbf{4}$ a) is therefore not suitable to describe this transient happening. If the reservoir was capable of providing an instantaneous response to the bottomhole pressure fluctuations, the pressure profile in the near wellbore would quickly readjust to the new wellbore conditions. However, due to a combination of inertia and compressibility effects, the reservoir response is not instantaneous and can even be particularly slow for tight formations. A sequence of conventional pressure profiles (Fig. 4 b) can be assumed, but this would imply a temporary discontinuity of the pressure function at the wellbore, which is physically impossible. Thus, the concept of $U$-shaped pressure profile is proposed as shown in Fig. 4 c. (Zhang et al., 2010; Limpasurat, 2013; Liu, 2016) 

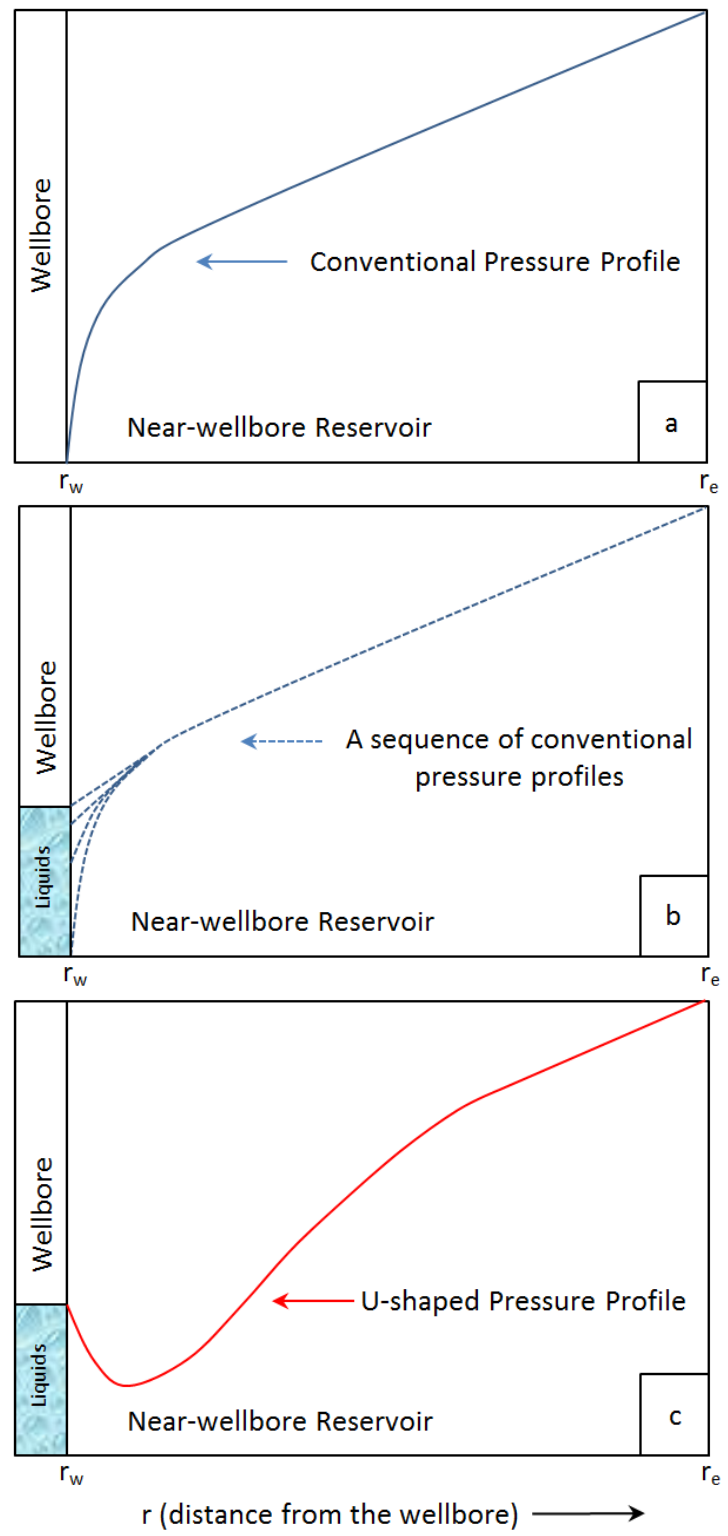

Fig. 4 - Pressure distribution of liquid unloaded and loaded wells along the near-wellbore reservoir, where $r_{w}$ is the wellbore radius and $r_{e}$ is the reservoir radius.

It is well known that fluids always flow from high pressure to low pressure. In this sense, the concept of the U-shaped curve suggests that accumulated liquids in the wellbore could be reinjected into the near wellbore region. An earlier approach to model re-injection was proposed by Dousi et al. (2006), through the definition of metastable gas flow on the basis of an analytical solution. According to the authors, the gas flow becomes metastable when a transient balance is achieved between the produced water at the wellhead and the water that is re-injected into the formation. This concept was later investigated by means of coupled wellbore/reservoir numerical simulations (Chupin et al., 2007; Limpasurat et al., 2015).

\section{Laboratory tests at core-scales}

One small-scale and one large-scale core-flooding experimental setups were designed and constructed to mimic the physical process of liquid loading and the corresponding reservoir response. To first prove the existence of the U-shaped pressure profile originally proposed by Zhang et al. (2010) while avoiding the laboratory complexities of handling two-phase flow, 
single gas nitrogen (purity $>=99.996 \%$ ) was used as the test fluid in this study. Obernkirchen sandstone, which is a very consolidated, relatively fine grained, low permeability sedimentary rock in the Lower Cretaceous, was selected for this study. The relevant components and properties of Obernkirchen sandstone are summarised in Table 2.

Table 2 - Components and properties of Obernkirchner Sandstone (Wang, 2012).

\begin{tabular}{|l|c|}
\hline Parameters & Values \\
\hline Quartz, \% & 92 \\
\hline Feldspar, \% & 3.5 \\
\hline Rock Fragments, \% & 1 \\
\hline Opaque Minerals, \% & 0.75 \\
\hline Heavy Minerals, \% & 0.75 \\
\hline Clay Minerals, \% & 2 \\
\hline Median Pore Size, $\mu \mathrm{m}$ & $15 \pm 10$ \\
\hline Porosity, \% & $15-20$ \\
\hline Permeability, mD & $5-20$ \\
\hline
\end{tabular}

The U-shaped temporal distribution of pore fluid pressure within the medium itself was successfully observed, in contrast to the conventional reservoir pressure profile.

\subsection{Experimental setup and procedure}

In this study, the small-scale and the large-scale experimental setups shared the same working principle and were operated under identical working conditions (pressures and temperatures). The major differentia difference is that a hydrostatic core holder was used in the large-scale scenario, which can accommodate a core sample with a length of $80 \mathrm{~cm}$ and a diameter of $10.16 \mathrm{~cm}$, instead of the Hassler cell used in the small-scale one, which can hold a core sample of $20.77 \mathrm{~cm}$ in length and $2.58 \mathrm{~cm}$ in diameter, to mimic a more realistic subsurface condition. In this section, only the experimental setup of the large-scale coreflooding tests is presented.

In the large-scale setup (Fig. 5), nitrogen from a gas cylinder was flooded through a pressurised core plug placed in a hydrostatic core holder. Both radial and axial confining pressures were provided, surrounding the core plug to mimic the overburden pressure in the reservoir. The confining pressure was set as a constant value of 8 barg during the tests. A custom-made elastic rubber sleeve, molded with fifteen pressure taps, was placed in the core holder. In this case, only four pressure taps were used, which were connected through pressure-port tubing to fixed distribution plugs, and then linked to pressure sensors by steel tubing to measure transient pressure profiles. In order to better measure the pressure profile at the interface between the core sample and gas storage tanks, these pressure taps were installed closer to the downstream of the system. Inlet and outlet pressures of the system were recorded by two extra pressure transducers at both ends of the core plug. During the tests, the opening position of a downstream three-way valve determined whether the produced gas should go to the gas storage tank 1 or the gas storage tank 2 in order to manually induce pressure surges from downstream. The produced pressure waves at the outlet were used to simulate a well/porous medium dynamical interface, where the core sample represented the near-wellbore reservoir and the two gas storage tanks characterised bottomhole pressure oscillations in the wellbore.

In the tests, the gas pressure provided by the gas cylinder were controlled by the upstream pressure regulator 1 at the outset of the system. Then, the tested gas was delivered into the inlet of the core sample, the gas storage tank 1 and the gas storage tank 2, respectively. Each component had its own gas regulator to manage the relevant gas pressures, the upstream pressure regulator 2 , the downstream pressure regulator 1 and the downstream 
pressure regulator 2 , respectively. These three precision gas regulators ensured an accurate pressure control up to 10 barg. Before each test, the tightness of the core holder was carefully checked to exclude any leakage; the gas storage tank 1 was connected to the atmosphere. Meantime, the pressure in gas storage tank 2 was regulated to 3 barg through the downstream pressure regulator 2. At the beginning of the test, the three-way valve was connected to tank 1 only and the inlet pressure was defined as constant at 5 barg by the upstream pressure regulator 2 . When gas flow had stabilized under this condition, the threeway valve was manually switched from tank 1 ( 0 barg) to tank 2 ( 3 barg), causing a sudden pressure increase at the end of the core sample. After a transient period, the gas flowed from the inlet to tank 2 under a new steady state condition. Pressure and flow rate distributions were recorded in the transient period between initial and final steady-state flowing conditions, where inlet pressure was maintained at a constant level while initiating a transient pressure build up at the core sample end.

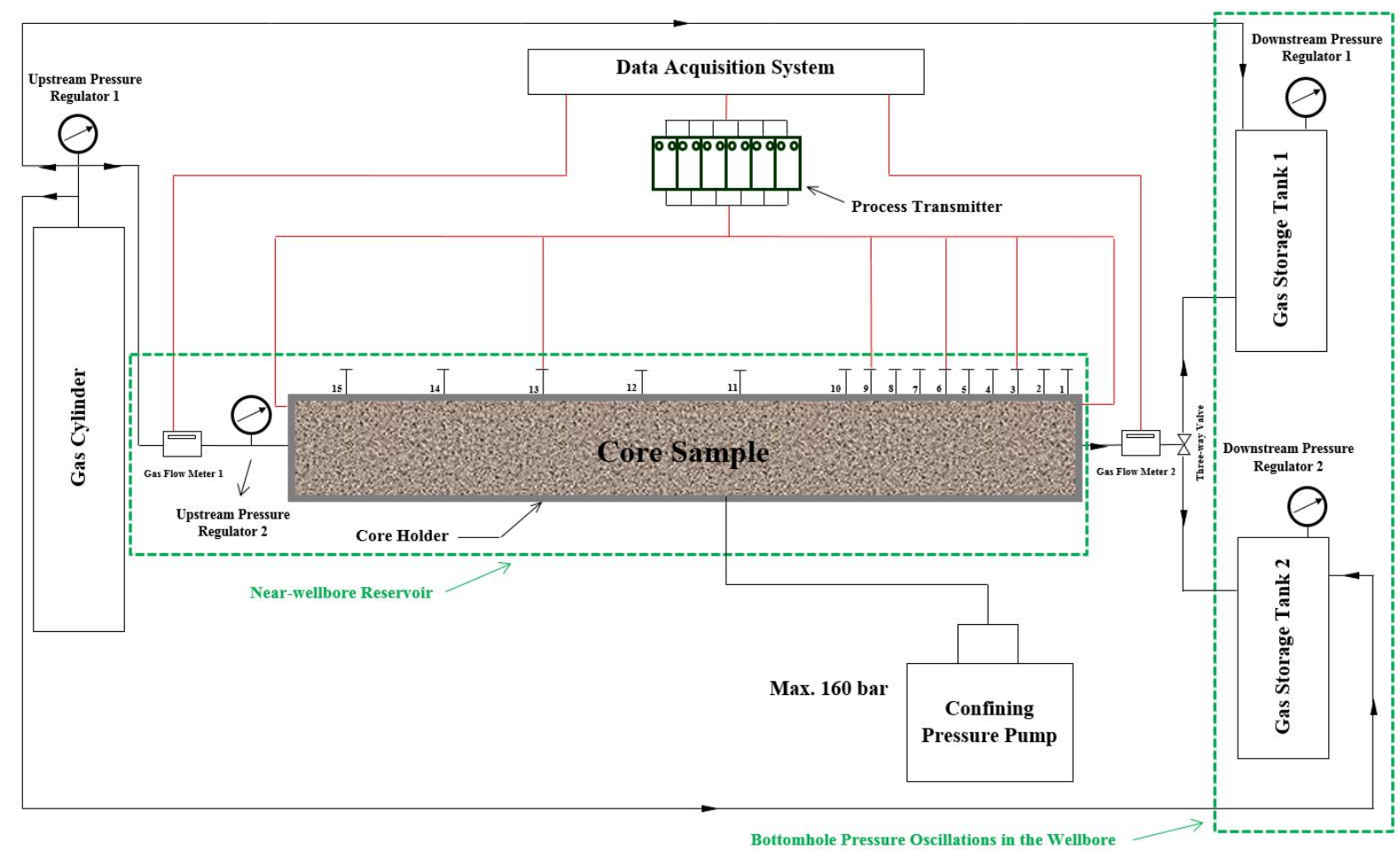

Fig. 5 - Schematic of the experimental setup for the large-scale laboratory tests. (Liu et al., 2016)

\subsection{Experimental results}

In what follows, the results of the small-scale and the large-scale core-flooding experiments are presented through time histories of pressure distributions and flow rates during the transient periods. The U-shaped curves can be clearly observed in the pressure profiles recorded during the transient period of both tests (Fig. 6). The transition from the initial steady state condition to the new one occurs rapidly in the experiments and the U-shaped pressure profile only appears over a relatively short time. The development of the U-shaped pressure profiles is slower than expected. The delayed responses at the measuring point "a" (see Fig. 6 A and B) are particularly obvious. During the experimental operation, the outlet pressure amplitude was manually controlled by the downstream three-way valve. Theoretically, the pressure value at point "a" should immediately increase from 0 barg to 3 barg at a time of $1 \mathrm{~s}(\mathrm{t}=1 \mathrm{~s})$. In practice, the outlet pressure takes around $2 \mathrm{~s}$ to reach the desired value in both tests. This mismatch is due to the data acquisition system requiring $1 \sim$ 
$2 s$ to respond to a pressure variation, yet the pressure transducers could only read the received signals after a rise time of $2 \sim 5 \mathrm{~ms}$. To qualitatively display the obtained experimental data, error propagation analyses are included in Fig. 6, by means of error bars, to indicate the closeness of the measured to the true values.
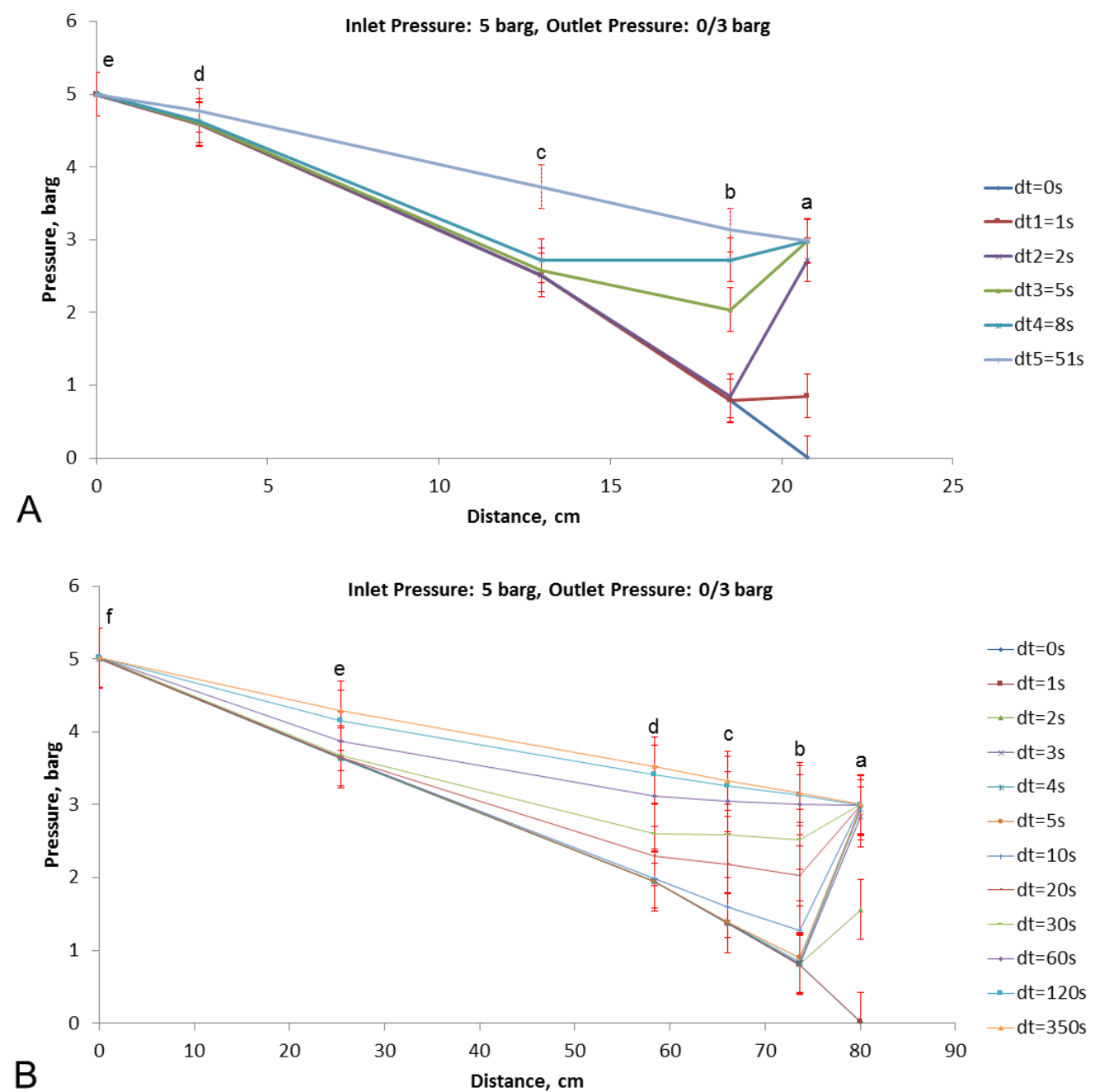

Fig. 6 - Pressure profiles during the transient period for the small-scale (A) and the large-scale (B) core-flooding experiments. (after Liu et al., 2016)

The upstream and downstream volumetric flow rates from the small-scale and the largescale tests were shown in Fig. 7 A and B. Both upstream flow rate profiles decreased initially during the transient period, as a smaller pressure drop along the core sample was generated with the imposed outlet pressures, and then became flat as the second steady state condition was reached. On the other hand, measurement gaps were observed in the downstream flow rate profiles of both experiments at the beginning of transient periods, indicating the occurrence of counter flow at the outlet of the system, as the flow meters used could only monitor gas flow in one direction. This observed experimental phenomenon corresponds to the re-injection from the wellbore into the reservoir during liquid loading in gas wells. Note that, due to the flow direction being overturned, the used flow meters needed time to stabilise. This explained the sudden bulge in Fig. 7 A. In Fig. 7 B, owing to the large scale of the core sample and the relatively high flow rate, the downstream flow rate profile did not fluctuate as much as the case in Fig. $7 \mathrm{~A}$. Therefore, there was no observed bulge in Fig. 7 B. Later on, both downstream flow rates flowed in the initial direction once more, 
indicating the end of counter flow. Finally, in both tests, gas flowed steadily through the core plug at a lower flow rate than the initial state, indicating that the second steady state condition had been attained. The transient periods between the first and the second steady state conditions only lasted for a few minutes in both experiments. The inlet and the outlet flow rates were nearly equal to each other under steady state conditions, as the volume flow rates displayed here were converted to standard pressure and temperature conditions adopted by the petroleum industry $\left(18^{\circ} \mathrm{C}\right.$ and 1 bara).
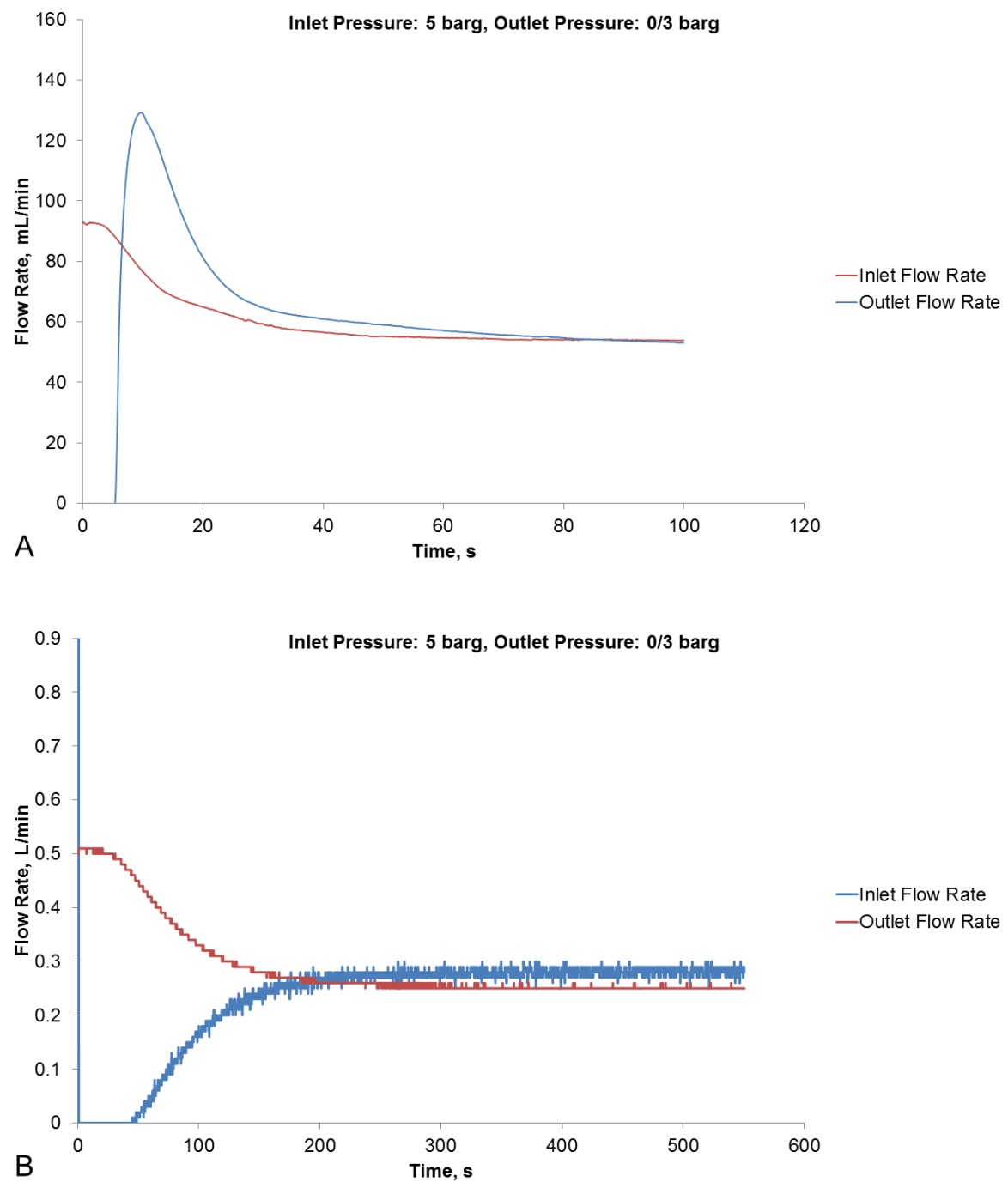

Fig. 7 - Comparison of inlet and outlet flow rates during the transient period for the smallscale (A) and the large-scale (B) core-flooding tests. (after Liu et al., 2016)

\section{Integrated wellbore/reservoir transient numerical modelling at reservoir-scale}

In order to consolidate the current core-scale understanding of the transient phenomena potentially associated with liquid loading and upscale it to a reservoir level, an integrated wellbore/reservoir model built with commercial software was applied to history match the production data from a liquid-loaded gas well located in northern Germany. The available production data consisted of surface gas/water flow rates, tubing head pressures, production/shut-in durations and relevant reservoir parameters, as provided by the field operator. 


\subsection{The target gas well}

The target gas well, which is located in northern Germany, was completed to a depth of 4987 $\mathrm{m}$ with a vertical 3.5 inch $(0.089 \mathrm{~m})$ tubing. The wellbore radius is $0.1 \mathrm{~m}$. The end of the tubing is positioned at $4652 \mathrm{~m}$. Production casing is cemented through the pay section from $4910 \mathrm{~m}$ to $4970 \mathrm{~m}$, which can be considered as two production intervals that were selectively perforated (see Fig. 8). The thickness of each interval is about $30 \mathrm{~m}$. The two reservoir layers were assumed to be in communication with one another. The initial reservoir temperature is around $150{ }^{\circ} \mathrm{C}$ at a depth of $4910 \mathrm{~m}$. The initial wellhead temperature is about $68{ }^{\circ} \mathrm{C}$. The porosity of the reservoir is $11 \%$, with a variable permeability of $0.2 \sim 4 \mathrm{mD}$. At the beginning of the well's production life, the average daily liquid gas ratio is around $16.4 \mathrm{~cm}^{3} / \mathrm{m}^{3}$ associated with an average gas production of $2.7 \times 10^{5} \mathrm{~m}^{3} /$ day.

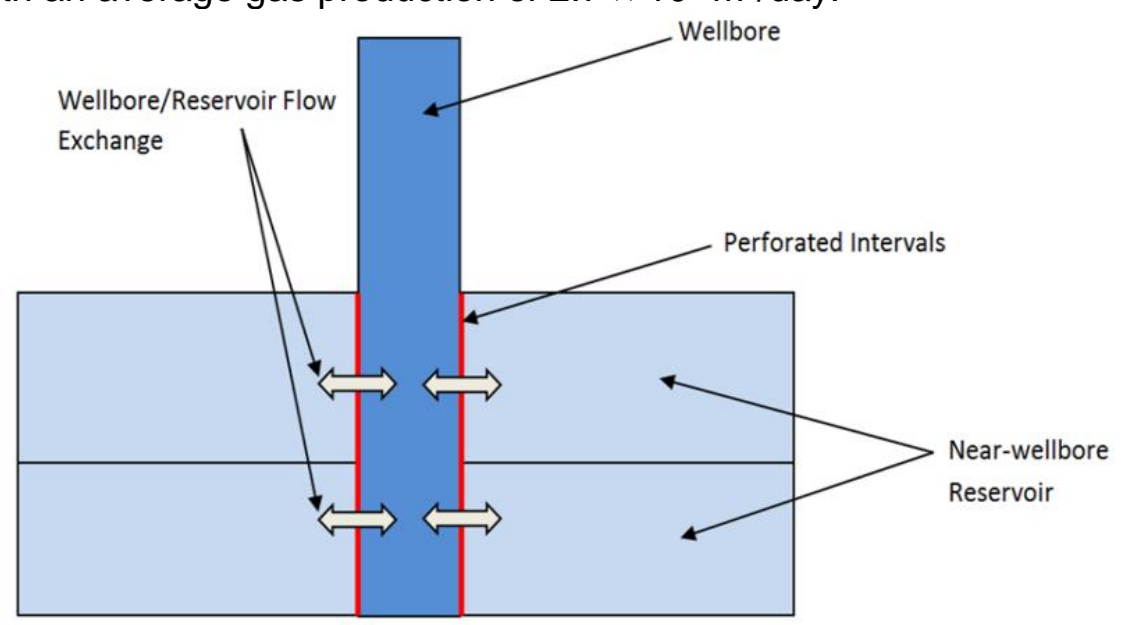

Fig. 8 - Schematic diagram of the target gas well with two reservoir layers.

This gas well had undergone controlled flow and shut-in cycles for 25 years. Well cycling is a commonly applied strategy to unload gas wells, which creates intermittent gas production by recurrently shutting the wells at surface, to extend their production life. During the cycling periods, the downhole hydrostatic head gradually builds up, potentially leading to the reinjection of the heavier phase into the reservoir. This caused an exchange between the wellbore and the reservoir flow as shown in Fig. 8. When the wells are opened up again, upwards gas flow can once again be achieved. As can be seen in Fig. 9, the gas production kept increasing at the first three years and then started to continuously decrease in the next 22 years under the influence of liquid loading.

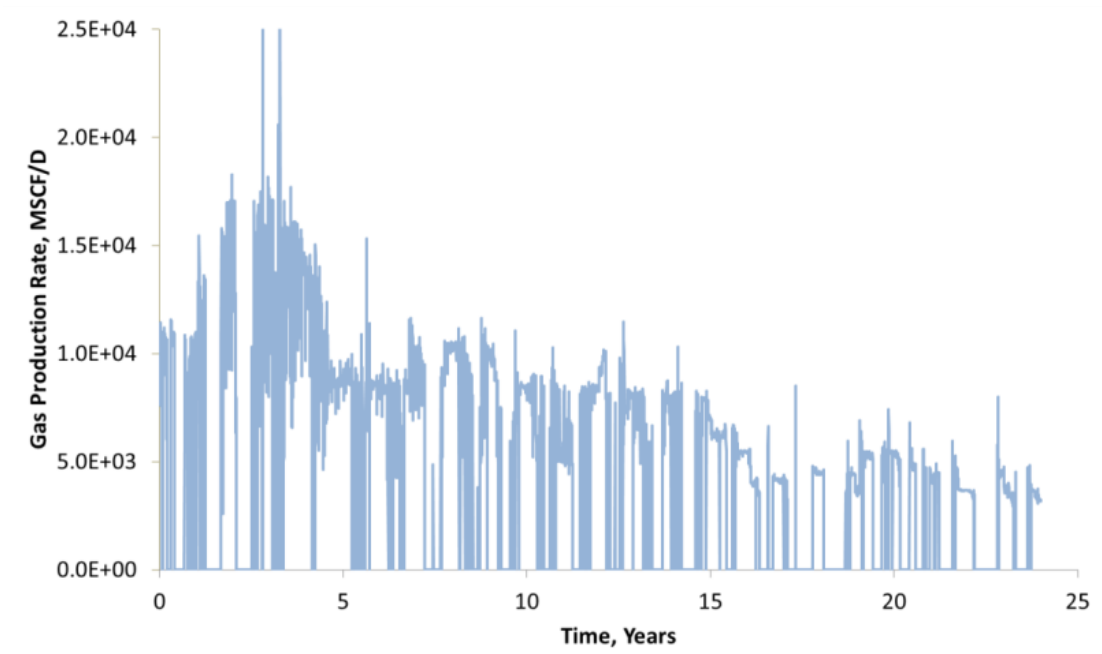

Fig. 9 - The recorded gas production rate at the wellhead of the target well. 


\subsection{Model Description}

An integrated wellbore/reservoir model was built to describe the target gas well. The selected commercial numerical software can implicitly connect a transient wellbore model to a transient near-wellbore reservoir model. The wellbore simulator (Bendiksen et al., 1991; Biberg et al., 2009) is one of the very few commercially available that could provide a sound consideration of dynamic flow features occurring in pipes and have the capability to model the entire production system from near-wellbore to wellhead. The near-wellbore module (Sagen et al., 2011) can be considered as a plug-in to the wellbore model in coupled simulations. The basic integration principle is that the wellbore model delivers the pressure boundary to the reservoir model, while the wellbore simulator receives the phase flow rates from the reservoir simulator. In the reservoir model, the reservoir is identified as a closed system that allows no flows in or out of the near-wellbore boundary. Its initial conditions are automatically determined on the basis of hydrostatic equilibrium in the near-wellbore region. The entire reservoir is assumed to be homogeneous and isotropic. The input parameters of the reservoir model is shown in Table 3 . Note that, reservoir permeability was calibrated for the simulations. The reservoir permeability is about 0.2 to $4 \mathrm{mD}$ from the database of the field operator, as extracted from well test interpretation. Here, the value of permeability was set to $1.5 \mathrm{mD}$ following history matching. The relative permeability and capillary pressure curves used in this study are shown in Fig. 10, which is also provided by the field operator.

Table 3 - Input parameters of the reservoir model

\begin{tabular}{|l|c|}
\hline Parameters & Values \\
\hline Grid $(\mathrm{x}, \mathrm{y}, \mathrm{z})$ & $5,2,2$ \\
\hline Flow geometry & Logarithmic-radial-cylindrical \\
\hline Fluid type in the reservoir & Methane and water \\
\hline Net to Gross & 1800 \\
\hline Drainage radius, $\mathrm{m}$ & 60 \\
\hline Reservoir thickness, $\mathrm{m}$ & 4910 \\
\hline The depth of the top reservoir, $\mathrm{m}$ & 11 \\
\hline Porosity, $\%$ & $1.5,1.5,1.5$ \\
\hline Permeability $(\mathrm{x}, \mathrm{y}, \mathrm{z}), \mathrm{mD}$ & $6.89 \mathrm{E}-08$ \\
\hline Rock compressibility, bar ${ }^{-1}$ & 540 \\
\hline $\begin{array}{l}\text { Reference pressure at which rock } \\
\text { compressibility is given, bar }\end{array}$ & Simulator customized \\
\hline Initial reservoir pressure, bar & Simulator customized \\
\hline Initial water saturation, $\%$ & 152 \\
\hline Reservoir temperature (constant), ${ }^{\circ} \mathrm{C}$ & 0.1 \\
\hline Wellbore radius, $\mathrm{m}$ &
\end{tabular}




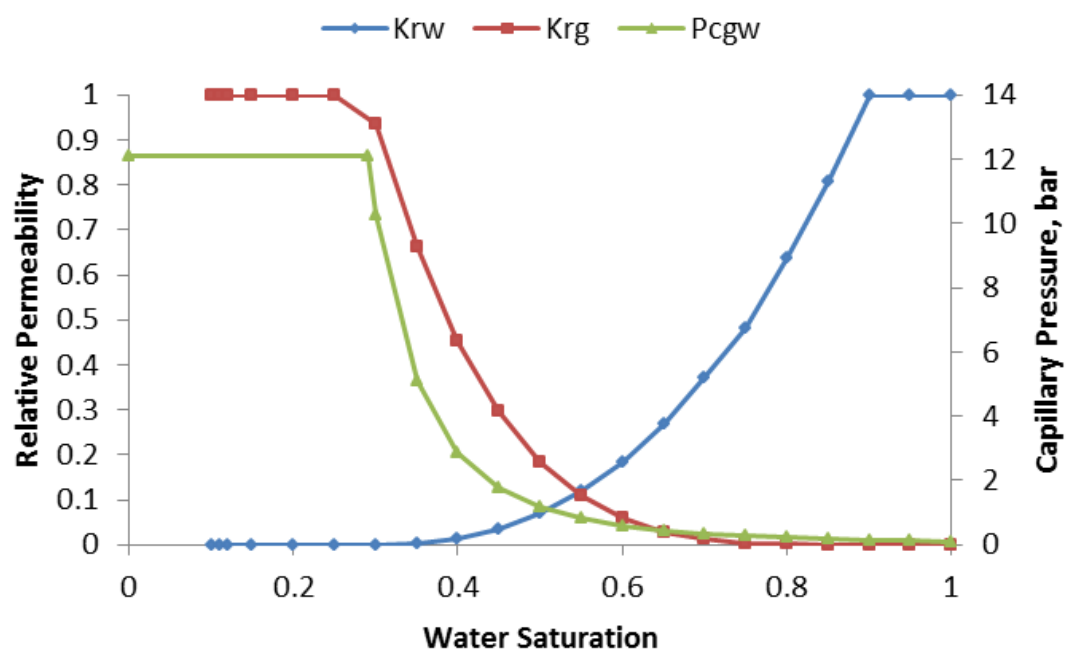

Fig.10 - Relative permeability and capillary pressure curves implemented in the reservoir model.

In the wellbore model, the initial tubing head pressure was set to $350 \mathrm{bar}$, based on actual field observations, and then controlled by a simulated valve on the wellhead to perform shutin and start-up activities, according to the sequence shown in Table 4.

Table 4 - Selected two cycles of well cycling

\begin{tabular}{|l|c|}
\hline Periods & Time, days \\
\hline Production & $1-25 ; 33-73$ \\
\hline Shut-in & $25-33 ; 73-110$ \\
\hline
\end{tabular}

The input parameters of wellbore simulator are summarised in Table 5. Fluids properties have a great impact on fluid flow in both the reservoir and the wellbore. For this coupled model, the PVT data are described by a look-up table shared by the wellbore model and the reservoir model, consisting of $98 \%$ methane and $2 \%$ water. Once the locations of corresponding numerical sections in the wellbore model and in the reservoir model are defined, the two simulators are automatically linked. Thus, there is no need to pre-define a boundary at the interface of the coupled model.

Table 5 - Input parameters of the wellbore model

\begin{tabular}{|l|c|}
\hline Parameters & Values \\
\hline Initial wellhead pressure, bar & 350 \\
\hline Wellhead temperature, ${ }^{\circ} \mathrm{C}$ & 68 \\
\hline Well depth, $\mathrm{m}$ & 4987 \\
\hline Perforation depth, $\mathrm{m}$ & 4925,4955 \\
\hline Tubing inner radius, $\mathrm{m}$ & 0.04 \\
\hline Fluid type in the wellbore & Methane and water \\
\hline
\end{tabular}

The transient flow along the near-wellbore region of the reservoir was expected to be a timedependent function of the integrated wellbore/reservoir system, as anticipated by the previous core-flooding experiments, where - however - the duration of the transient periods only lasted a few minutes. Therefore, small time steps (1 to 100s) were set in the model to capture short-term dynamics, which significantly slowed down the simulation. Two actual cycles were selected from the intermittent production (see Table 4) to be modelled, each including one production and one shut-in period. The simulations presented here aimed at comparing laboratory time scales with real field time scales, by simulating 110 days of production from the test gas well while it was suffering from liquid loading. Some particular 
instances of intermittent response from the near-wellbore reservoir were noted in the simulation results.

\subsection{Simulation Results}

The history matching results of surface gas/water flow rates and tubing head pressure are shown in Fig. 11, 12 and 13, respectively. There is a great agreement between actual and simulated data, which validated the basic accuracy of the modelling effort.

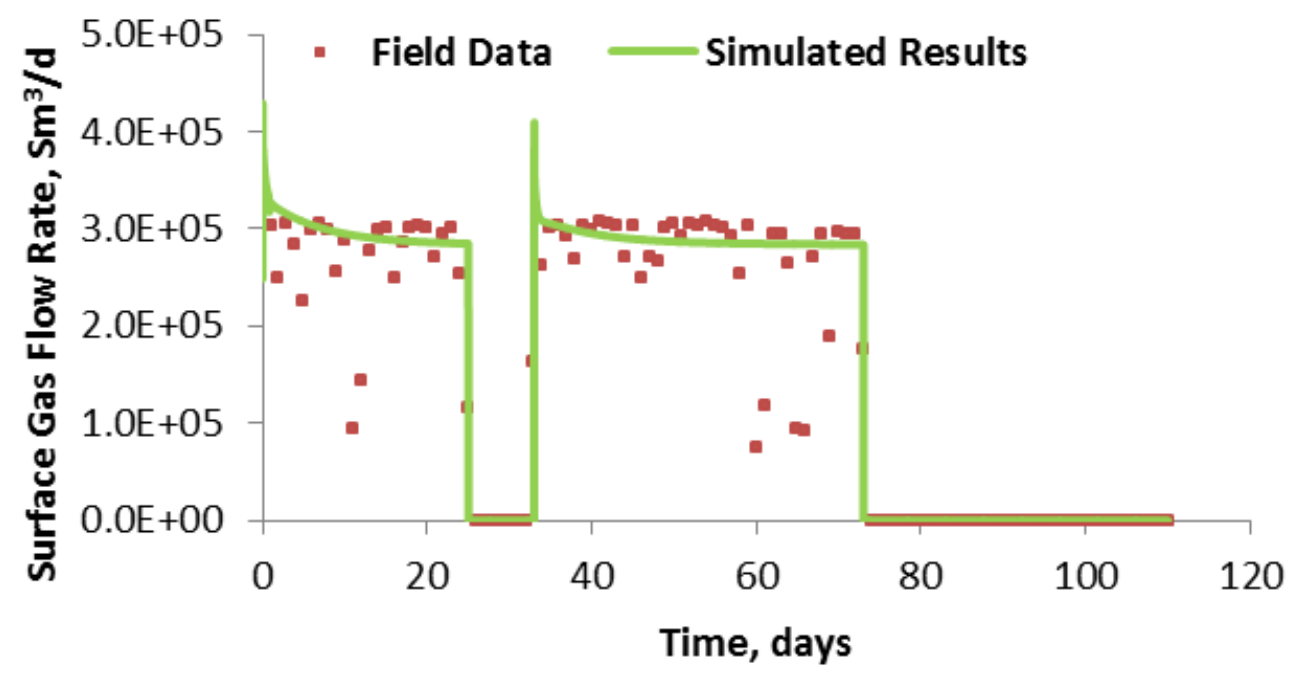

Fig. 11 - Comparison of actual and simulated surface gas flow rates during production and shut-in periods.

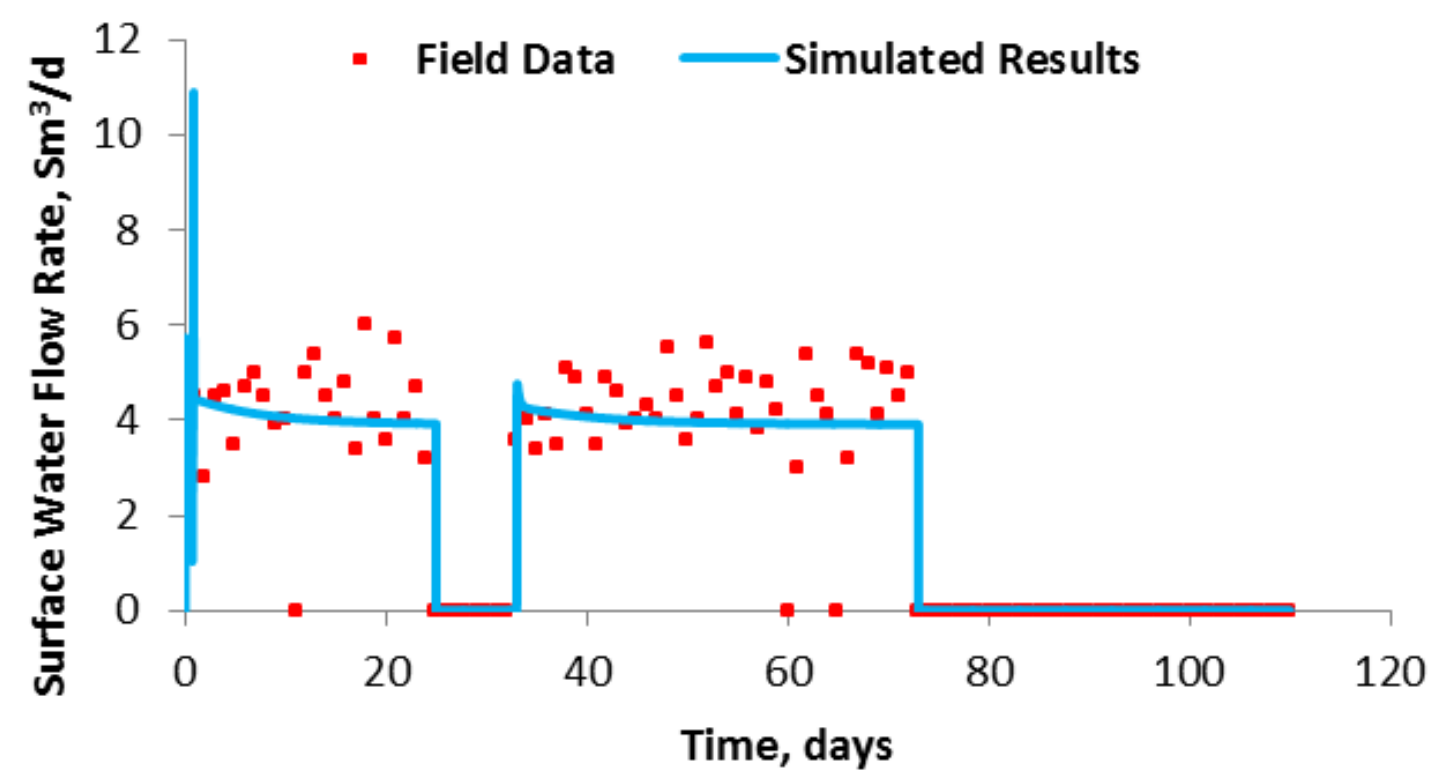

Fig. 12 - Comparison of actual and simulated surface water flow rates during production and shut-in periods. 


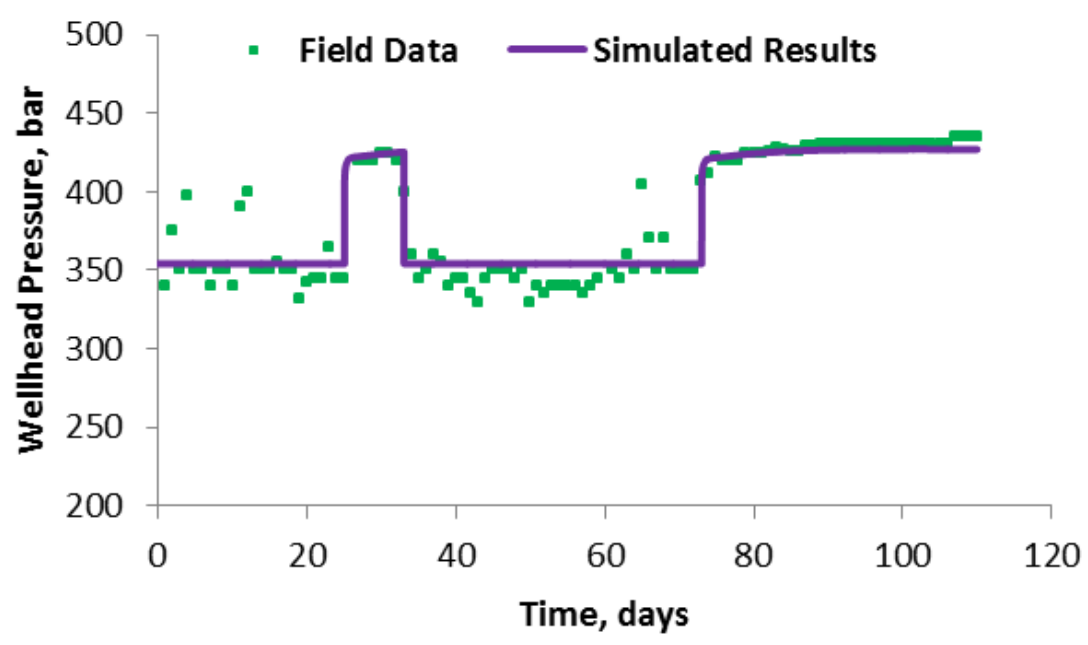

Fig. 13 - Comparison of actual and simulated wellhead pressure during production and shutin periods.

Fig. 14 shows the simulated water flow rates at the inner boundary (bottomhole) during the second shut-in period (from the day 73 to the day 110). It can be noted that, at the very beginning of the shut-in period, the bottomhole water flow rate in the upper layer shows the same trend as that in the lower layer. As soon as the well is closed, the rates increase in the negative direction (indicating re-injection), and then they start to level off to near zero. Although the water flow rate is very close to zero at the end of the shut-in, the water phase is still being re-injected with an extremely small negative rate in both reservoir intervals $(<$ $0.0002 \mathrm{Sm}^{3} /$ day; see the zoom-in part of Fig. 14). The negative water flow rates represent the re-injection behavior of denser phase into the reservoir, which appears to persist throughout the entire shut-in period. This phenomenon is corresponding to the observed counter flow in the core-flooding experiments (see Fig. 7).

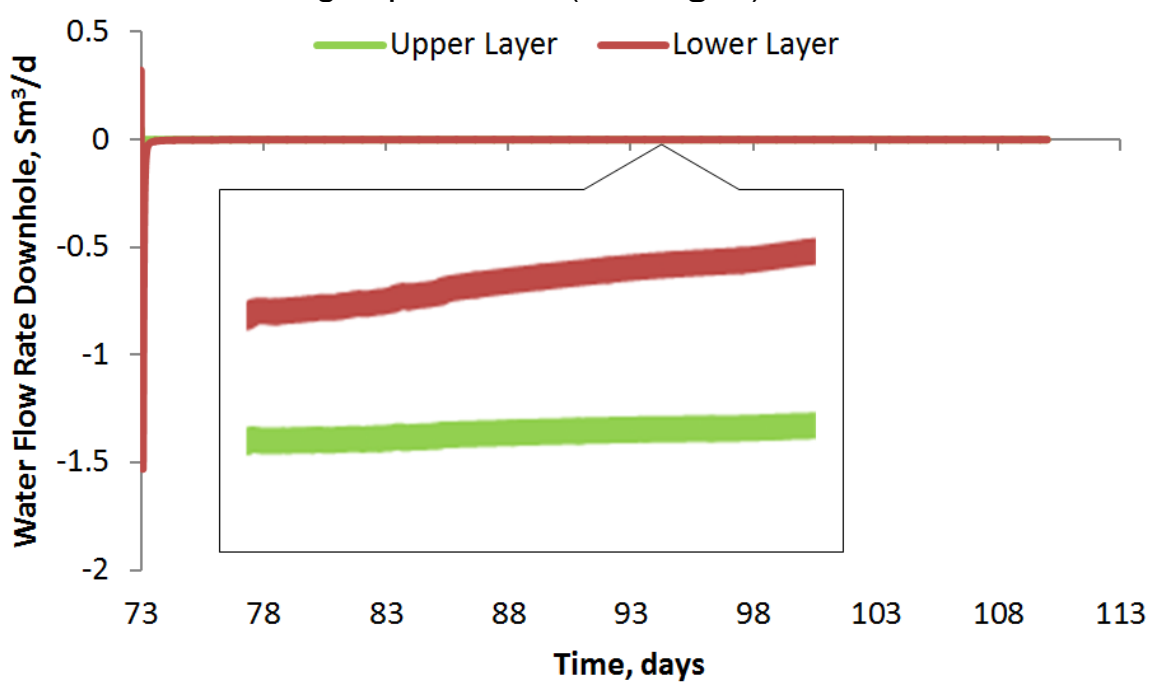

Fig. 14 - Water flow rates at the inner boundary during the second shut-in period.

Compared to water, gas performs in a very different way, as shown in Fig. 15. As soon as the wellhead valve is closed, due to inertia effects, the gas entering the well from both reservoir layers gradually decreases, maintaining positive rates. Then the gas flow rate in the lower layer becomes negative, while that in the upper layer remains positive. The two values cancel out, suggesting that the same amount of gas that is produced by the upper layer gets re-injected into the lower layer during the shut-in. 


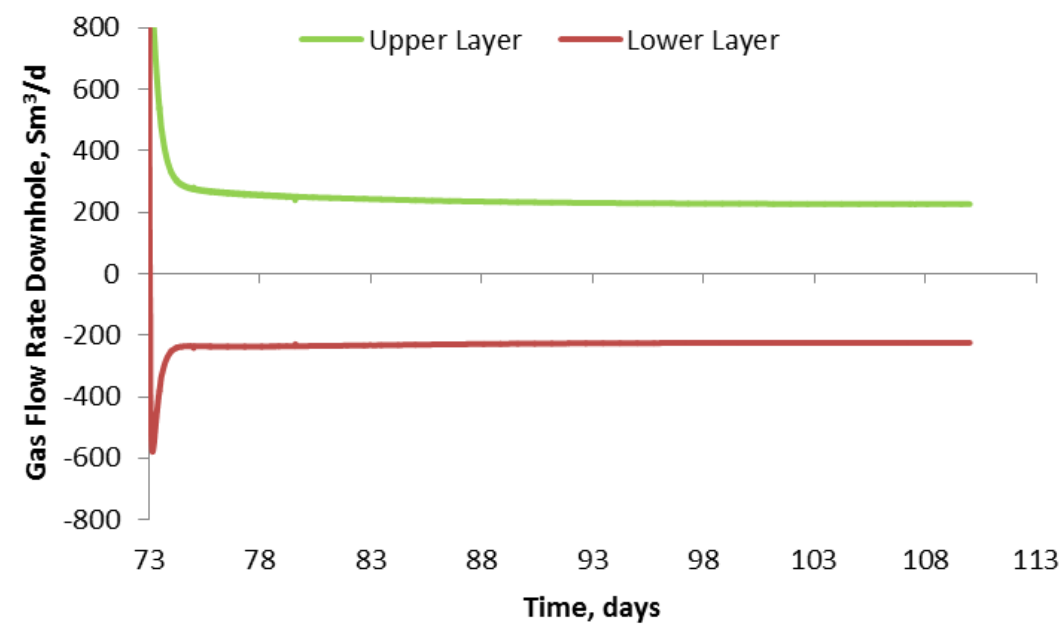

Fig. 15 - Gas flow rates at the inner boundary during the second shut-in period.

Fig. 16 shows the saturation profiles of water and gas for both of reservoir layers along the near-wellbore region on the $75^{\text {th }}$ day (two days after the well is closed) and on the $110^{\text {th }}$ day (end of shut-in), respectively. On the $75^{\text {th }}$ day, water saturation in the block that is closest to the wellbore is higher than that in any other blocks of reservoir, indicating that water reinjection has taken place in this section of near-wellbore region. After approximately 35 days of shut-in, most of water has moved into the next adjacent reservoir, causing the latter to have highest water saturation.
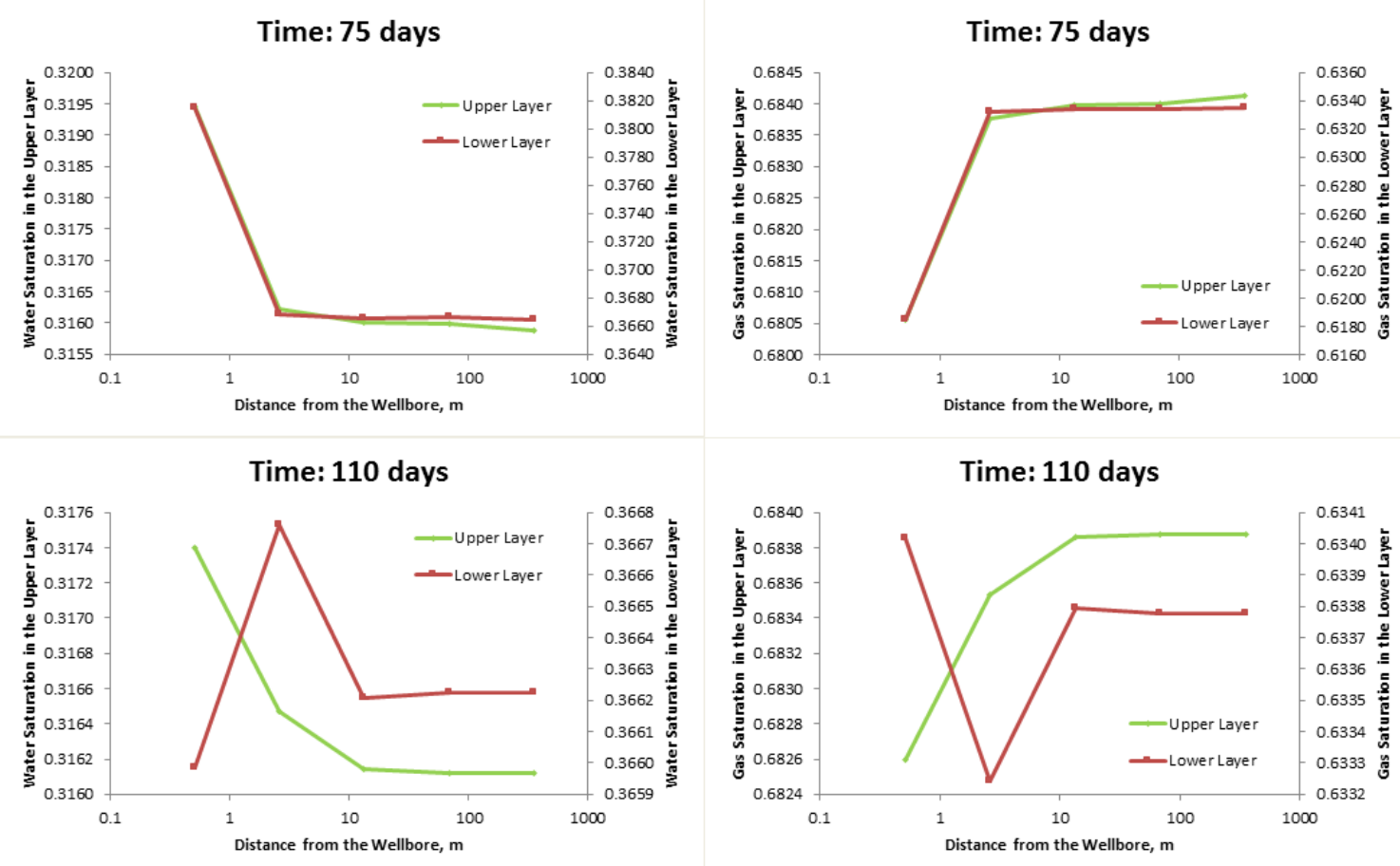

Fig. 16 - Saturation profiles along the near-wellbore region at different points in time during the second shut-in period. The horizontal axis captures the distance from the wellbore center to the logarithmic center point of each block.

As illustrated in Fig. 17, the simulated water/gas phase pressure profiles in the near-wellbore 
region for both reservoir layers show the anticipated U-shape and reflect the bottomhole flow rates already presented in Fig. 14 and Fig. 15. For the gas phase, at 110 days, the pressure profile along the near-wellbore region in the lower layer is U-shaped, while that in the upper layer is conventionally distributed, agreeing with the flow direction in both layers (see Fig. 15).

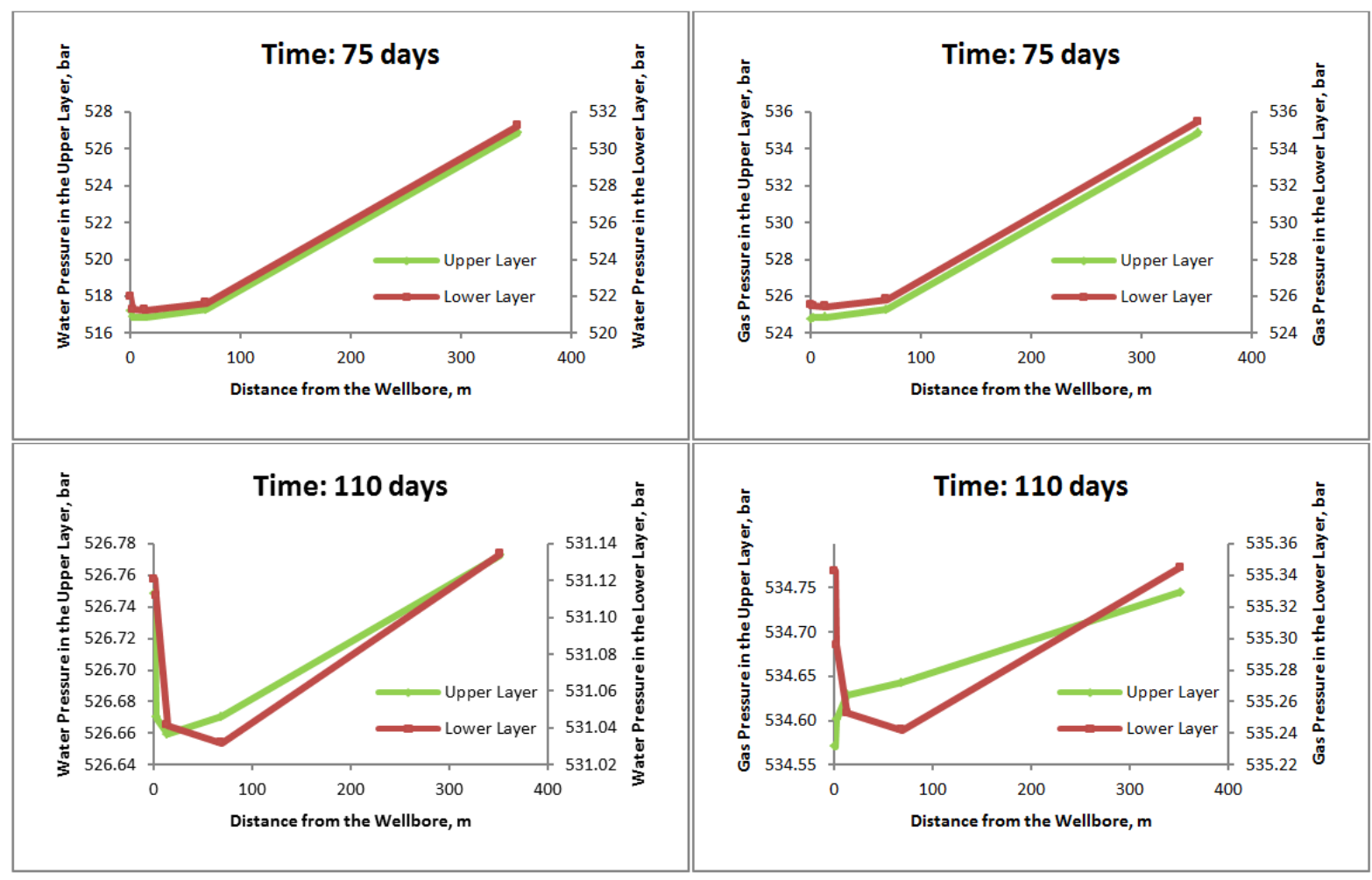

Fig. 17 - Pressure profiles along the near-wellbore region at different points in time during the second shut-in period. The horizontal axis captures the distance from the wellbore center to the logarithmic center point of each block.

In this particular study, time steps 1 to 100 s were set to capture short-term dynamics, which is very small comparing to normal reservoir simulation steps (days, months or even years). This set-up significantly slowed down the running time of the simulations. Thus, only the first two actual cycles from the start of intermittent production (see Table 4) were modelled. Even so, the current model would require 10 hours for running. The target gas well had been suffering from liquid loading since the beginning of its 25 years production history. The loaded situation was the least dramatic at the beginning of its production life, which is the case would simulated here. Over time, the liquid loading situation would become more and more serious (causing larger pressure difference), causing a significant influence on the gas production. As can be seen in Fig. 9, the gas production at the end of its life is just half of that at the beginning. In addition, relatively large pressure differences have been observed in the experimental results.

\section{Conclusions}

In this study, two different scales core-flooding experimental setups were designed and calibrated to investigate the existence of transient pressure profiles in the near-wellbore region under liquid loading conditions. Based on experimental observations, the U-shaped pressure distribution can be established during the dynamic interactions between wellbore and reservoir. In addition, the transition from the initial steady state condition to the new one 
occurs rapidly in the tests and the U-shaped pressure profile only appears over a relatively short time.

In order to consolidate the understanding of the transient phenomena that were experimentally obtained at the core-scale, and to upscale this understanding for it to be applicable at the reservoir-scale, an integrated wellbore/reservoir model was built using commercial software to history match the production data from a liquid-loaded gas well with an operational history of 25 years. With the intention of providing a comparison between laboratory and real field time scales, the built model focused on a time period of 110 days with simulation time steps of 1 to 100s. The simulation results showed that surface gas/water flow rates and tubing head pressures history could be closely matched by the modelling approach described in this paper. In parallel, the transient characteristics of short-term downhole dynamics were observed in the numerical simulation, such as re-injection and cocurrent/counter-current flows. The observed U-shaped pressure profiles in the core-flooding experiments were verified and numerically upgraded to reservoir scale. The simulated pressure dynamic bottomhole response, and pressure and distributions of each phase during consecutive production and shut-in periods captured the U-shaped concept along the nearwellbore region.

Consequently, the experimental and numerical results in this study suggested that liquid reinjection could occur during liquid loading in gas wells due to wellbore phase-redistribution. The presence of the U-shaped pressure profiles might explain the re-injection behavior of denser phase into the near-wellbore reservoir.

\section{Acknowledgement}

The authors would like to thank RWE Dea A.G. (now DEA Deutsche Erdoel AG), the sponsor of the Joint Industry Project on Liquid Loading in the Operation of Gas Field: Mechanisms, Prediction and Reservoir Response (Phase II) for financing this research.

\section{Reference}

Belfroid, S.P.D., Schiferli, W., Alberts, G.J.N., Veeken, C.A.M. and Biezen, E., 2008. Predicting Onset and Dynamic Behaviour of Liquid Loading Gas Wells, SPE-115567-MS, SPE Annual Technical Conference and Exhibition, Colorado, USA, https://doi.org/10.2118/115567-MS.

Bendiksen, K.H., Malnes, D., Moe, R. and Nuland, S., 1991. The Dynamic Two-Fluid Model OLGA: Theory and Application, SPE Production Engineering, Vol. 6, Issue 02, pp. 171-180, https://doi.org/10.2118/19451-PA.

Biberg, D., Holmas, H., Staff, G., Sira, T., Nossen, J., Andersson, P., Lawrence, C., Hu, B. and Holmas, K., 2009. Basic Flow Modeling for Long Distance Transport of Wellstream Fluids, the 14th International Conference on Multiphase Production Technology, Cannes, France.

Chupin, G., Hu, B., Haugset, T., Sagen, J. and Claudel, M., 2007. Integrated Wellbore/Reservoir Model Predicts Flow Transient in Liquid-Loaded Gas Wells, SPE 110461, SPE Annual Technical Conference and Exhibition, Caledonia, USA, https://doi.org/10.2118/110461-MS.

Coleman, S.B., Clay, H.B., McCurdy, D.G., and Lee Norris, H. III, 1991. A New Look at Predicting Gas-Well Load Up, Journal of Petroleum Technology, Vol. 43, Issue 03, pp. 95-97, https://doi.org/10.2118/20280-PA.

Denney, D., 2007. Integrated Wellbore/Reservoir Model Predicts Flow Transients in Liquid-Loaded Gas Wells, Journal of Petroleum Technology, Vol. 59, Issue 11, pp. 329-333, https://doi.org/10.2118/1107-0095-JPT.

Dousi, N., Veeken, C.A.M. and Currie, P.K., 2006. Numerical and Analytical Modelling of the Gas Well Liquid Loading Process, SPE Production \& Operations, Vol. 21, Issue 04, pp. 475-482, https://doi.org/10.2118/95282-PA. 
Fernandez, J., Falcone, G. and Teodoriu, C., 2010. Design of a High-Pressure Research Flow Loop for the Experimental Investigation of Liquid Loading in Gas Wells, SPE Projects, Facilities \& Construction, Vol. 5, No. 2, pp. 76-88, https://doi.org/10.2118/122786-PA.

Guo, B., Ghalambor, A. and Xu, C., 2006. A Systematic Approach to Predicting Liquid Loading in Gas Wells, SPE Production and Operations, Vol. 21, Issue 01, pp. 81-88, https://doi.org/10.2118/94081$\underline{P A}$.

Hu, B., Veeken, K., Yusuf, R. and Holmas, H., 2010. Use of Wellbore-Reservoir Coupled Dynamic Simulation to Evaluate the Cycling Capability of Liquid-Loaded Gas Wells. SPE Annual Technical Conference and Exhibition, Florence, Italy, http://dx.doi.org/10.2118/134948-MS.

Lea, J.F., Nickens, H.V., and Wells, M., 2003. Gas Well De-Liquefaction, first edition, Elsevier Press, Cambridge, MA, ISBN: 9780080477985.

Li, M., Li, S.L. and Sun, L.T., 2002. New View on Continuous-Removal Liquids from Gas Wells, SPE Production \& Facilities, Vol. 17, Issue 01, pp. 42-46, https://doi.org/10.2118/75455-PA.

Limpasurat, A., 2013. Coupled Modeling of Dynamic Reservoir/Well Interactions under Liquid-Loading Conditions, Ph.D. Dissertation, Department of Petroleum Engineering, Texas A\&M University, College Station, Texas, USA.

Limpasurat A., Valko, P. and Falcone G., 2015. A New Concept of Wellbore-Boundary Condition for Modeling Liquid Loading in Gas Wells, SPE Journal, Vol. 20, Issue 03, pp. 550-564, https://doi.org/10.2118/166199-PA.

Liu, X., 2016. Experimental and Numerical Investigation of Transient Gas and Gas-Liquid Flows in Integrated Reservoir/Wellbore Systems under Liquid Loading Conditions, Ph.D. Dissertation, Institute of Petroleum Engineering, Clausthal University of Technology, Clausthal-Zellerfeld, Germany, ISBN: 9783869484969 .

Liu, X., Falcone, G. and Teodoriu, C., 2016. Liquid Loading in Gas Wells: Experimental Investigation of Back Pressure Effects on the Near-Wellbore Reservoir, Journal of Natural Gas Science and Engineering, Vol. 36, Issue Part A, https://doi.org/10.1016/j.jngse.2016.10.064.

Luan, G. and He, S., 2012. A New Model for the Accurate Prediction of Liquid Loading in LowPressure Gas Wells, Journal of Canadian Petroleum Technology, Vol. 51, Issue 06, pp. 493-498, https://doi.org/10.2118/158385-PA.

Nosseir, M.A., Darwich, T.A., Sayyouh, M.H., and El Sallaly, M., 2000. A New Approach for Accurate Prediction of Loading in Gas Wells under Different Flowing Conditions, SPE Prod. \& Facilities, Vol. 15, Issue 04, pp. 241-246, https://doi.org/10.2118/66540-PA.

Sagen, J., Ostenstad, M., Hu, B., Irgens H., Lien, S., Xu, Z., Groland, S., And Sira, T., 2011. A Dynamic Model for Simulation of Integrated Reservoir, Well and Pipeline System, SPE Annual Technical Conference and Exhibition, Colorado, USA, https://doi.org/10.2118/147053-MS.

Schiferli, W., Belfroid, S.P.C., Savenko, S., Veeken, C.A.M. and Hu, B., 2010. Simulating Liquid Loading in Gas Wells, 7th North American Conference on Multiphase Technology, Banff, Canada.

Sutton, R.P., Cox, S.A., Lea, J.F. and Rowlan, O.L., 2010. Guidelines for the Proper Application of Critical Velocity Calculations, SPE Production \& Operations, Vol. 25, Issue 2, pp. 182-194, https://doi.org/10.2118/120625-PA.

Turner, R.G., Hubbard, M.G., and Dukler, A.E., 1969. Analysis and Prediction of Minimum Flow Rate for the Continuous Removal of Liquids from Gas Wells, J. Pet. Tech., pp1475-1482, https://doi.org/10.2118/2198-PA. 
Van't Westende, J.M.C., 2008. Droplets in annular-dispersed gas-liquid pipe flows, Ph.D. Dissertation, Delft University of Technology, ISBN: 9789064642081.

Veeken, C.A.M. and Belfroid, S.P.C., 2010. New Perspective on Gas-Well Liquid Loading and Unloading, SPE Annual Technical Conference and Exhibition, Florence, Italy, https://doi.org/10.2118/134483-PA.

Veeken, K., Bakker, E. and Verbeek, P., 2003. Evaluating Liquid Loading - Field Data and Remedial Measures, Gas Well Deliquification Workshop, Colorado, USA.

Waltrich, P.J., 2012. Onset and Subsequent Transient Phenomena of Liquid Loading in Gas Wells Experimental Investigation Using a Large Scale Flow Loop, Ph.D. Dissertation, Department of Petroleum Engineering, Texas A\&M University, College Station, Texas, USA.

Wang, Y., 2012. Investigation on the Near Wellbore Transient Flow under Liquid Loading Conditions in Gas Wells, Papierfieger Verlag GmbH, Ph.D. Dissertation, Clausthal University of Technology, Germany, ISBN: 978869482255.

Zhang, H., Falcone, G., and Teodoriu, C., 2010. Modelling Fully-Transient Two-phase Flow in the Near-Wellbore Region During Liquid Loading in Gas Wells, Journal of Natural Gas Science \& Engineering, Vol. 2, Issues 2-3, 122-131, https://doi.org/10.1016/i.jngse.2010.04.005.

Zhou, D. and Yuan, H., 2010. A New Model for Predicting Gas-Well Liquid Loading, SPE Production \& Operations, Vol. 25, Issue 2, pp. 172-181, https://doi.org/10.2118/120580-PA. 